\title{
Analysis on the Status Quo and Influencing Factors of the "Five Conceptions and Six Features" Community Courtyard Pension Model in Nanchang
}

\author{
Xing Liu1, Xiang Li¹, Bin Liu1, Yu Wei¹, Jin-Yuan Zhang², Ping Zhang², He-Lang Huang1* \\ ${ }^{1}$ Department of Epidemiology and Health Statistics, School of Public Health, Jiangxi Province Key Laboratory of Preventive \\ Medicine, Nanchang University, Nanchang, China \\ ${ }^{2}$ Nanchang Nightingale Volunteer Service Team, Nanchang, China \\ Email: hhlang0821@sina.com
}

How to cite this paper: Liu, X., Li, X., Liu, B., Wei, Y., Zhang, J.-Y., Zhang, P. and Huang, H.-L. (2018) Analysis on the Status Quo and Influencing Factors of the "Five Conceptions and Six Features" Community Courtyard Pension Model in Nanchang. Open Journal of Social Sciences, 6, 66-72. https://doi.org/10.4236/jss.2018.66006

Received: May 1, 2018

Accepted: May 20, 2018

Published: May 23, 2018

\begin{abstract}
Objective: Analysis on the status quo and influencing factors of the Community Courtyard Pension Model in Nanchang. Methods: A unified questionnaire and interviews were conducted to collect relevant information. Result: The survey obtained 590 valid questionnaires and interviews. The analysis suggested that $77.1 \%$ of the respondents chose "Five conceptions and Six features" Community Courtyard Pension Model and there were significant differences in gender, educational level, occupation, monthly income, health status and illness or not $(\mathrm{P}<0.05)$. Logistic regression indicates that gender, monthly income and illness are important for choosing the pension model. Conclusion: The choice of community pension mode depends on the individual's biological and sociological characteristics or needs. The "Five conceptions and Six features" Community Courtyard Pension Model has good applicability, though it is influenced by various factors of the individual and the community.
\end{abstract}

\section{Keywords}

Pension Mode, Influencing Factors, Elderly Population, Community Service

\section{Introduction}

According to the statistics of our country in 2016, the population aged 60 and above reached 229 million, accounting for $16.60 \%$ of the total population. By 2020 , the level of aging in our country will reach $17.17 \%$. By 2050 , the elderly 
population will account for $1 / 4$ [1]. With the accelerating aging and the first-generation single-child parents entering the old age period, the " $4-2-1$ " and the "8-2-1" family model are rapidly increasing, which greatly aggravated the support burden for the family. This has become an unavoidable issue for many families [2] [3] [4]. It is estimated that the elderly population in Nanchang has reached $15 \%$ with a total of 525,000 people. The number of elderly people able to stay in public pension institutions accounts for only $2.85 \%$, which can not meet a large number of needs for the aged [5]. In view of this situation, the government and the whole society are actively promoting various models such as home care, community support, housing endowment, and so on [6] [7] [8] [9] [10]. In Nanchang, apart from home-based care, community care has become an important form of pension model. In particular, with the establishment and improvement of various facilities and service functions such as the Internet + , and the gradual formation of a series of systems such as a harmonious family, a friendly neighborhood and a Well-off society, it has greatly benefited the society's pension business. The "Five conceptions and Six features" Community Courtyard Pension Model is the preliminary framework, which is based on the long-term cooperation between the project group and the "Nanchang love service group", and is welcomed by the large population. The model based on the theory of life sciences, demand and supply management, humanities, this project applied the intelligent information technology and modern management method to build an innovative pension mode, whose core is "the Five Conceptions" including full human-based, full resource-pooling, full-network intelligent, comprehensive health care and full-course standardized, whose main content included "six great modules", financial support, everyday life care, spiritual comfort, the medical care, real estate maintenance and emergency assistance, and which used "courtyard" as basic unit [11] [12].

This study uses interview and questionnaire survey, combined with literature review and the previous research practice of this project group, comprehensively analyzes the influencing factors of urban community residents' pension mode selection, and explores the solutions in accordance with the actual situation in Nanchang.

\section{Data and Methods}

\subsection{Inclusion and Exclusion Criteria of the Study Object}

Inclusion criteria Residents aged 30 and above, no difficulty in communication, willingness to participate in surveys and obtain informed consent. Exclusion criteria People who are temporarily living in urban communities, unwilling to participate in the survey, patients with serious diseases who cannot complete the full survey program.

\subsection{Research Sites and Samples}

Three communities of Xiao Jin Tai, Qingshan Lake and Bao Jiaxiang of Nanchang were selected. The positive rate $(\pi)$ of the elderly (aged 60 and above) is 
$16.60 \%$, the test level $(\alpha)=0.05$ (bilateral), and the allowable error $(\delta)=0.2 \pi$. Considering the loss of the tested objects, the sample size is increased by $10 \%$ and the sample size is about 530. In the field investigation, 590 valid questionnaires were obtained, which was $11.32 \%$ above the planned sample.

\subsection{Method and Content of Investigation}

Communicate with the subjects and fill in the self-made questionnaire. Training of investigators included unified inclusion criteria, familiarity with the purpose and content of the investigation. The survey includes 11 aspects, including basic information, current living conditions (economic income, health status, medical insurance, etc.), the view and attitude of the pension mode.

\subsection{Statistical Analysis}

Using EpiData 3.1 software to build database for double entry. SPSS 17.0 software was used to analyze the data. Chi-square test and Logistic regression were used for statistical analysis, $\alpha=0.05$.

\section{Results}

\subsection{Demographic Characteristics and Pension Intention of the Subjects.}

455 people (77.12\%) chose courtyard pension model, and another 135 (22.88\%) chose to be supported by their children and pensions in professional organizations among 590 respondents. The majority of the respondents were women, which was $64.41 \%$. There were differences in the choice of old-age care between different genders. $64.74 \%$ of people aged 60 and above, $35.26 \%$ of those under 60 years old. The distribution of different educational level is more uniform with slightly more "junior high school". Occupational distribution is uneven, "workers" and "government units, enterprises, institutions" are mostly. The vast majority of respondents had children, except for six individuals (1.02\%). After the chi-square test, except for age, the number of children, the monthly pension cost, the family relationship and the money support, the differences among the other six factors were statistically significant, as shown in Table 1.

\subsection{Analysis on the Influencing Factors of the Selection among the Courtyard Pension Model}

We set "whether to choose the Courtyard pension mode" as dependent variable $(\mathrm{Y})$, and the independent variable $(\mathrm{X})$ which was through single factor analysis, variable assignment on Table 2 . The method selected into the in-equation variable was Forward: Wald ( $\alpha_{\text {in }}=0.05, \alpha_{\text {out }}=0.10$, each variable was compared with the assigned value of " 1 " except for the level data). There are three variables that ultimately enter the regression equation, which are gender, monthly income and whether or not they are sick. The results showed that women had a slightly lower desire than men to participate in Courtyard pension model. The higher the 
Table 1. Demographic characteristics of respondents and main influencing factors of pension choices.

\begin{tabular}{|c|c|c|c|c|c|c|}
\hline \multirow{2}{*}{\multicolumn{2}{|c|}{ Characteristic }} & \multicolumn{2}{|c|}{ Courtyard pension model } & \multirow{2}{*}{ Total } & \multirow{2}{*}{$x^{2}$} & \multirow{2}{*}{$P$} \\
\hline & & Yes & No & & & \\
\hline \multirow{2}{*}{ Gender } & Male & $176(83.81)$ & $34(16.19)$ & $210(35.59)$ & 8.272 & 0.004 \\
\hline & Female & $279(73.42)$ & $101(26.58)$ & $380(64.41)$ & & \\
\hline \multirow{4}{*}{ Education } & Primary & $82(67.77)$ & $39(32.23)$ & $121(20.51)$ & 10.982 & 0.012 \\
\hline & Junior & $143(76.47)$ & $44(23.53)$ & $187(31.69)$ & & \\
\hline & High & $125(78.62)$ & $34(21.38)$ & $159(26.95)$ & & \\
\hline & College & $105(85.37)$ & $18(14.63)$ & $123(20.85)$ & & \\
\hline \multirow{6}{*}{ Occupation $^{a}$} & Worker & $213(78.31)$ & $59(21.69)$ & $272(46.26)$ & 16.133 & 0.006 \\
\hline & Farmer & $18(62.07)$ & $11(37.93)$ & $29(4.93)$ & & \\
\hline & Institutions & $175(81.02)$ & $41(18.98)$ & $216(36.73)$ & & \\
\hline & Freelance & $20(80.00)$ & $5(20.00)$ & $25(4.25)$ & & \\
\hline & Housework & $16(53.33)$ & $14(46.67)$ & $30(5.10)$ & & \\
\hline & Others & $11(68.75)$ & $5(31.25)$ & $16(2.72)$ & & \\
\hline \multirow{5}{*}{$\begin{array}{l}\text { Income per } \\
\text { month/yuan }\end{array}$} & $\leq 1000$ & $28(58.33)$ & $20(41.67)$ & $48(8.14)$ & 13.717 & 0.008 \\
\hline & $1000-$ & $100(76.34)$ & $31(23.66)$ & $131(22.20)$ & & \\
\hline & $2000-$ & $276(78.19)$ & $77(21.81)$ & $353(59.83)$ & & \\
\hline & $4000-$ & $44(88.00)$ & $6(12.00)$ & $50(8.47)$ & & \\
\hline & $\geq 6000$ & $7(87.50)$ & $1(12.50)$ & $8(1.36)$ & & \\
\hline \multirow{4}{*}{ Health status } & Well & $338(78.42)$ & $93(21.58)$ & $431(73.05)$ & 8.210 & 0.042 \\
\hline & Self-care & 109 (75.17) & $36(24.83)$ & $145(24.58)$ & & \\
\hline & Attend & $8(66.67)$ & $4(33.33)$ & $12(2.03)$ & & \\
\hline & Bedridden & $0(0.00)$ & $2(100.00)$ & $2(0.34)$ & & \\
\hline \multirow{2}{*}{ Illness ${ }^{\mathrm{a}}$} & Yes & $267(81.40)$ & $61(18.60)$ & $328(55.97)$ & 6.587 & 0.010 \\
\hline & No & $187(72.48)$ & $71(27.52)$ & $258(44.03)$ & & \\
\hline
\end{tabular}

Note a, the data has missing values.

Table 2. Variable Assignment

\begin{tabular}{cl}
\hline Variable & Assignment \\
\hline Gender & $1=$ Male, $2=$ Female \\
Education & $1=$ Primary, $2=$ Junior, $3=$ High, $4=$ College \\
Occupation & $1=$ Worker, $2=$ Farmer, $3=$ Institutions, $4=$ Freelance, $5=$ Housework, \\
6 Income per month & $1=\leq 1000,2=1000-2000,3=2000-4000,4=4000-6000,5=\geq 6000$ \\
Health status & $1=$ Well, $2=$ Self-care, $3=$ Attend, $4=$ Bedridden \\
Illness & $1=$ Yes, $2=$ No
\end{tabular}


monthly income, the lower the willingness to participate in the Courtyard pension model. The patient population is less willing to choose the Courtyard pension model than the unaffected population, as shown in Table 3.

\section{Discussion}

With economic and social development, human life expectancy has been extended by 10 - 20 years in recent decades [13] [14]. The accumulation of the elderly population has brought great challenges to individuals, families and society [15]. The rate of the only child in the survey was $50.68 \%$. Compared with the traditional home care, the children's support pressure was relatively higher. Based on the reality of China, the model can meet the needs of the elderly, such as family emotion and social care, which is in line with the wishes of the majority of the elderly.

The results of this study suggest that gender is related to the selection intention of the pension model. Women are more inclined to live together with their children than men, while men are more independent. Many middle-aged and older women are looking after their grandchildren and providing family support for their children, such as shopping, cooking, housework. Due to traditional concepts and social attributes, women's social activities are less than men's. They are generally insecure and need family support. This survey results show that there are differences in the choice of pension modes among the people with different educational levels and occupations. People with high educational level, wide working communication and rich social relations prefer to choose the model of community. The reason is that these groups are mostly rich and colorful in their living arrangements in their old age, and they need free communication and recreational activities. They are unwilling to be confined to the unified management of the nursing homes. Logistic regression shows that monthly income is negatively correlated with this choice of pension mode, which may be due to low-income people unable afford a high institutional pension costs. The study also found that illness is related to the choice of pension mode. As the symptoms of the disease are aggravated and the health condition is poor, the old people have to depend on their children because they can not take care of themselves completely. This is the main reason why they choose to live together with their children as a pension model, as $44.03 \%$ of the population in this survey was ill. The Courtyard pension model takes into account the health needs of

Table 3. Logistic Regression Analysis on the Choice of Pension Model

\begin{tabular}{cccccc}
\hline Variable & $\beta$ & SE & Wald & P & OR(95\%CI $)$ \\
\hline Gender & -0.542 & 0.228 & 5.674 & 0.017 & $0.581(0.372,0.908)$ \\
Income per month & -0.391 & 0.132 & 8.858 & 0.003 & $0.676(0.523,0.875)$ \\
Illness & -0.646 & 0.203 & 10.153 & 0.001 & $0.524(0.352,0.780)$ \\
constant & 0.333 & 0.377 & 0.783 & 0.376 & 1.396 \\
\hline
\end{tabular}


many elderly people, it highlights "comprehensive health care" in "the Five Conceptions" and "everyday life care, the medical care, emergency assistance" in "Six Features". At the same time, the model relies on the community to manage the health records of the elderly and integrate medical services into home-based care. The development of the combination of medical care and home-based care for the elderly will help achieve a healthy and active aging. The community is the smallest unit in which people gather in the city. Aged wants to spend the rest of their lives in their familiar environment. The "Five conceptions and Six features" Community Courtyard Pension Model can effectively reduce the burden on children and provide elderly people with more efficient, satisfactory old-age care services, so that elderly people with different levels and different needs can be satisfied with their old-age living. It will provide an important reference for exploring and putting forward the model of health care for sustainable development in China.

\section{Acknowledgements}

We appreciate that the efforts the staff and volunteers made by working on aging in Xiao Jin Tai, Qingshan Lake and Bao Jiaxiang in Nanchang, China. We are also grateful to the students and teachers in School of Public Health, Nanchang University who participated in the data entry.

\section{Ethics Statement}

The study protocol was approved by the ethical review committee of The Second Affiliated Hospital of Nanchang University. All participants read a statement that explained the purpose of the survey and provided written informed consent before participation in the study.

\section{Disclosure Statement}

No potential conflict of interest was reported by the authors.

\section{Funding}

This work was funded by the National Natural Science Foundation of China, [grant number 71663037].

\section{References}

[1] People's Republic of China National Bureau of Statistics. China Statistical Yearbook [DB/OL]. http://www.stats.gov.cn/tjsj/ndsj/

[2] Zhang, L., Zeng, Y. and Fang, Y. (2017) The Effect of Health Status and Living Arrangements on Long Term Care Models among Older Chinese: A Cross-Sectional Study. Plos One, 12, e0182219. https://doi.org/10.1371/journal.pone.0182219

[3] Torres-Gil, F.M. (2016) The Evolution of Gerontology and Geriatrics in an Era of a Politics of Aging. Gerontol Geriatr Educ, 2016, 1-5.

[4] Song, Q. (2016) The Speedy Ageing Population: Severe Challenges for Social Endowment Services in China. Theory Journal. 
[5] Zhou, Y.J. (2017) Study on the Construction of Urban Residents' Pension Mode Based on the Background of Aging in Nanchang. Nanchang University.

[6] Nygård, M., Härtull, C., Wentjärvi, A., et al. (2017) Poverty and Old Age in Scandinavia: A Problem of Gendered Injustice? Evidence from the 2010 GERDA Survey in Finland and Sweden. Social Indicators Research, 132, 1-18. https://doi.org/10.1007/s11205-016-1313-6

[7] Prince, M.J., Lloydsherlock, P., Guerra, M., et al. (2016) The Economic Status of Older People's Households in Urban and Rural Settings in Peru, Mexico and China: a 10/66 INDEP Study Cross-Sectional Survey. Springerplus, 5, 1-16. https://doi.org/10.1186/s40064-016-1913-2

[8] Reeves, A., Mckee, M., Mackenbach, J., et al. (2017) Public Pensions and Unmet Medical Need among Older People: Cross-National Analysis of 16 European Countries, 2004-2010. Journal of Epidemiology \& Community Health, 71, 174-180. https://doi.org/10.1136/jech-2015-206257

[9] Banks, J., Crawford, R. and Tetlow, G. (2015) Annuity Choices and Income Drawdown: Evidence from the Decumulation Phase of Defined Contribution Pensions in England. Journal of Pension Economics \& Finance, 14, 412-438. https://doi.org/10.1017/S1474747215000256

[10] Murata, J., Mitsuda, M., Itakura, T., et al. (2016) The Home Care Situation for the Elderly and an Evaluation of Their Environment. Journal of Environmental Engineering, 81, 599-606. https://doi.org/10.3130/aije.81.599

[11] Huang, H.L. (2016) The Construction of Building (Yard) Style Endowment Pattern Informationized with "Five Conceptions Six Features" in Aging Society and Its Rethinking. Chinese Health Service Management.

[12] Yao, L. (2015) A Research about the Age-Supporting Status and "Building (Yard) Style" Endowment Pattern of Xiaojintai Community in Nanchang. Chinese Health Service Management.

[13] Christensen, P.K., Doblhammer, P.G., Rau, P.R., et al. (2017) Ageing Populations: the Challenges Ahead. Lancet, 374, 1196. https://doi.org/10.1016/S0140-6736(09)61460-4

[14] Chen, W. (2018) Human Capital, Life Expectancy, and the Environment. Journal of International Trade \& Economic Development, 26, 1-22. https://doi.org/10.1080/09638199.2018.1430164

[15] Alghatrif, M., Wang, M., Fedorova, O.V., et al. (2017) The Pressure of Aging. Medical Clinics of North America, 101, 81-101. https://doi.org/10.1016/j.mcna.2016.08.006 